\title{
The Effects of Glucose Load on Catabolism during Remifentanil-Based Anesthesia in Patients with Diabetes Mellitus: A Prospective Randomized Trial
}

\author{
Maiko Hasegawa-Moriyama*\#, Mayumi Nakahara*, Takayuki Saito, Tomotsugu Yamada, \\ Keika Mukaihara, Mina Masuda, Akira Matsunaga, Yuichi Kanmura \\ Department of Anesthesiology and Critical Care Medicine, Graduate School of Medical and Dental Sciences, \\ Kagoshima University, Kagoshima, Japan \\ Email: "hase-mai@m3.kufm.kagoshima-u.ac.jp, nakahara@m3.kufm.kagoshima-u.ac.jp, \\ taksaito@m2.kufm.kagoshima-u.ac.jp, tmtg-ymd@m2.kufm.kagoshima-u.ac.jp, d-keika@goo.jp, \\ mm37@m3.kufm.kagoshima-u.ac.jp, matunaga@m3.kufm.kagoshima-u.ac.jp, \\ kanmura@m3.kufm.kagoshima-u.ac.jp
}

Received 19 June 2015; accepted 19 July 2015; published 22 July 2015

Copyright (C) 2015 by authors and Scientific Research Publishing Inc.

This work is licensed under the Creative Commons Attribution International License (CC BY). http://creativecommons.org/licenses/by/4.0/

c) (i) Open Access

\section{Abstract}

Background: General anesthesia using remifentanil may suppress the unwanted metabolic changes caused by surgical stress including hyperglycemia and ketogenesis. Surgery-related changes in catabolism can be attenuated with low-dose glucose load, without causing hyperglycemia. However, the impact of glucose load in diabetic patients during surgery is unknown. In this study, we investigated the effect of glucose load on catabolism during remifentanil-based anesthesia in patients with diabetes mellitus. Methods: Twenty-nine patients with diabetes mellitus undergoing elective surgery were randomly assigned to receive a glucose load $(1.5 \mathrm{mg} / \mathrm{kg} / \mathrm{min})$ or not. Plasma levels of glucose, insulin, cortisol, dopamine, adrenaline, noradrenaline, acetoacetic acid, free fatty acid, ketone bodies, 3-hydroxybutyric acid, and 3-methylhistidine/creatinine, a marker of protein catabolism were measured at the start of surgery and $3 \mathrm{~h}$ after the start of surgery. Results: Glucose and insulin levels were significantly higher in patients who received a glucose load than in those who did not. Cortisol levels decreased at $3 \mathrm{~h}$ after the start of surgery in both groups whereas the levels of catecholamines were unchanged. Acetoacetic acid and total ketone body levels were significantly lower in patients given a glucose load than in those who were not $3 \mathrm{~h}$ after the start of surgery. The difference in the 3-methylhistidine/creatinine ratio between the two groups was not significant. Conclusions: The infusion of glucose suppressed lipid catabolism in diabetic

\footnotetext{
*These authors contributed equally to this work.

${ }^{\#}$ Corresponding author.

How to cite this paper: Hasegawa-Moriyama, M., Nakahara, M., Saito, T., Yamada, T., Mukaihara, K., Masuda, M., Matsunaga, A. and Kanmura, Y. (2015) The Effects of Glucose Load on Catabolism during Remifentanil-Based Anesthesia in Patients with Diabetes Mellitus: A Prospective Randomized Trial. Open Journal of Anesthesiology, 5, 155-162.

http://dx.doi.org/10.4236/ojanes.2015.57028
} 
patients under remifentanil-based anesthesia during surgery. Our study also suggests that in patients with diabetes mellitus, protein sparing is inhibited by remifentanil-based anesthesia, regardless of the glucose load. Trial registration: the University Hospital Medical Information Network identifier: UMIN000010914.

\title{
Keywords
}

\author{
Diabetes, Remifentanil, Glucose Infusion, Catabolism
}

\section{Introduction}

Glucose tolerance during anesthesia is induced by the stress response to surgery and includes the release of catecholamines and stress hormones such as cortisol, leading to hyperglycemia. However, the lack of a glucose load during surgery may accelerate protein catabolism aimed at compensating for energy expenditures [1]. Nonetheless, the hyperglycemic state induced by a glucose load may lead to postoperative complications including the attenuation of the immune response to infection, delayed wound healing, and increased mortality [2]. Conversely, the increase in fat catabolism induced by hypoglycemia may cause ketoacidosis and the elevation of plasma free fatty acids, both of which are linked to sudden death due to the increase in myocardial oxygen consumption and the induction of arrhythmia [3]. Therefore, the benefits of the administration of an intraoperative glucose load are unclear. Moreover, in diabetic patients, the efficacy of intraoperative glucose infusion has not been well investigated. Several studies have shown that a glucose load decreases the production of ketone bodies and protein catabolism in patients anesthetized with fentanyl [4]. However, in patients undergoing cardiopulmonary bypass, the plasma level of cortisol is higher in patients under fentanyl-based anesthesia than under remifentanil-based anesthesia, suggesting that the two agents induce different types of stress response in surgical patients [5]. A recent study showed that the infusion of low-dose glucose attenuated fat catabolism without inducing hyperglycemia in patients under remifentanil-based anesthesia [6]. Therefore, remifentanil may effectively inhibit both protein sparing without inducing hyperglycemia and the secretion of stress hormones regulating glucose homeostasis. Although the effects of glucose infusion for energy metabolism during surgery have been examined [7], whether a glucose load affects the catabolism of fat and proteins induced by surgical stress in diabetic patients under remifentanil-anesthesia are unclear. Therefore, in this study we investigated the effects of glucose load on fat and protein catabolism in diabetic patients under remifentanil-based anesthesia.

\section{Methods}

Thirty-four elective surgery patients with American Society of Anesthesiologists Physical Status II who were previously diagnosed with diabetes mellitus according to the guideline of the Japan Diabetic Society (fasting plasma glucose level $>126 \mathrm{mg} / \mathrm{dl}$ and $75 \mathrm{~g}$ OGTT $>200 \mathrm{mg} / \mathrm{dL}$, or glycosylated hemoglobin [the National Glycohemoglobin Standardization Program] $>6.5 \%$, or casual plasma glucose level $>200 \mathrm{mg} / \mathrm{dL}$ ) were enrolled from August 2013 to July 2014. The patients were randomly assigned to receive a glucose load $G(+)$ or a non-glucose load G(-) (Figure 1). The fasting time of all patients was $8 \mathrm{~h}$ prior to the operating room entrance. No patient was premedicated. After arrival in the operating room, a $20 \mathrm{G}$ catheter was inserted into the patient's forearm and bicarbonate Ringer's solution was infused. Patients in the $G(+)$ group were administered a $10 \%$ glucose solution with glucose-free bicarbonate Ringer's solution at the rate of $1.5 \mathrm{mg} / \mathrm{kg} / \mathrm{min}$. General anesthesia was induced by the intravenous administration of propofol $(1.5 \mathrm{mg} / \mathrm{kg})$, remifentanil $(0.3-0.5 \mu \mathrm{g} / \mathrm{kg} / \mathrm{min})$, and rocuronium bromide $(0.6 \mathrm{mg} / \mathrm{kg})$, and maintained with sevoflurane (endotidal $\geq 1.0 \%)$ and remifentanil $(0.1$ - $0.5 \mu \mathrm{g} / \mathrm{kg} / \mathrm{min}$ ). Rocuronium bromide was given intermittently based on train-of-four monitoring. Changes in the infusion rate of a glucose-free plasma substitute within $5-10 \mathrm{~mL} / \mathrm{kg} / \mathrm{min}$ were allowed, depending on bleeding volume and hemodynamic changes. Plasma concentration of glucose was measured every 1 hour. Insulin was intravenously administered in case that plasma concentration of glucose exceeded $200 \mathrm{mg} / \mathrm{dL}$. The tidal volume was set at $8 \mathrm{~mL} / \mathrm{kg}$, the respiratory rate at $10-12 / \mathrm{min}$, and the $\mathrm{O}_{2} /$ air mixture at $\mathrm{FiO}_{2} 0.4-0.5$ to maintain an end-tidal $\mathrm{CO}_{2}$ of $35-40 \mathrm{mmHg}$. Patients receiving glucose infusion before operation, corticosteroids and blood transfusion in the perioperative periods were excluded from the study. 


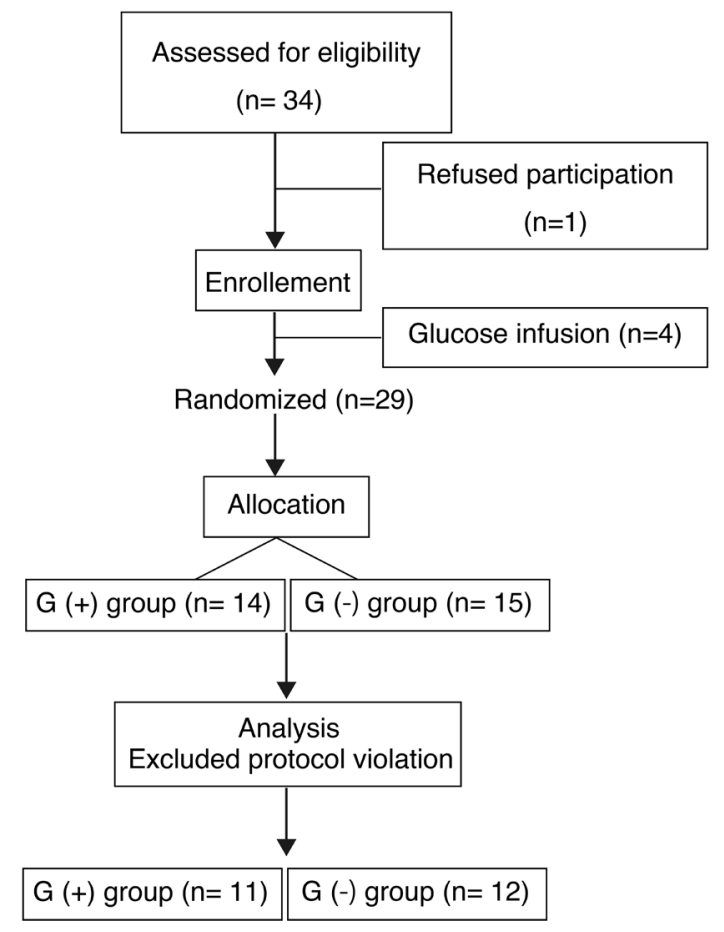

\begin{abstract}
Figure 1. Patient distribution. Among the 34 patients eligible for the study, one patient refused participation. Four patients were excluded because of glucose infusion before operation. The remaining 29 patients were randomized to the glucose load $\mathrm{G}(+)$ or the non-glucose load $\mathrm{G}(-)$ group. After the analysis, 6 patients were excluded because of protocol misconduct, surgery $<3 \mathrm{~h}$, blood transfusion, or corticosteroid administration during surgery.
\end{abstract}

The study was approved by the Ethics Committee of Kagoshima University Hospital (No. 25 - 18) on May 31 2013, and registered with the University Hospital Medical Information Network Center (ID: UMIN000010914). Informed consent was obtained from all patients enrolled in this study.

\title{
2.1. Measurements
}

Blood samples were obtained at the start of surgery and $3 \mathrm{~h}$ later. Blood samples were centrifuged at $150 \mathrm{~g}$ at $4^{\circ} \mathrm{C}$ for $10 \mathrm{~min}$, and plasma and serum samples were stored at $-20^{\circ} \mathrm{C}$ until the analysis. Plasma glucose was measured by the hexokinase UV method, plasma catecholamines by catecholamine tests, and urine 3-methylhistidine (3-MH) by high-performance liquid chromatography. Serum levels of free fatty acids, ketone bodies, acetoacetic acid, 3-hydroxybutyric acid and creatinine (Cr) were measured enzymatically, serum insulin by a chemiluminescent enzyme immunoassay and serum cortisol by a radioimmunoassay. The assays were performed by SRL Inc (Tokyo, Japan).

\subsection{Statistical Analysis}

The primary end point was determined based on the previous studies [4] [6]. The minimum number of patients in each group was 11 , with an alpha of 0.05 and a power of $80 \%$. Demographic data were analyzed using an unpaired $t$-test and the Chi-squared test. The difference between groups was evaluated using a two-way analysis of variance followed by the Bonferroni test. Data are presented as mean \pm standard deviation. A $P$ value $<0.05$ was considered statistically significant. All statistical analyses were performed with Prism 5 (Graph Pad Software Inc., San Diego, CA, USA).

\section{Results}

One patient was excluded because of refused participation. Four patients were excluded because of glucose in- 
fusion before operation. Three from the G(+) group and the G(-) group for each were excluded because of protocol misconduct, surgery shorter than $3 \mathrm{~h}$, blood transfusion, or corticosteroid administration during surgery (Figure 1). The characteristics of patients (Table 1) and the types of surgical procedures (Table 2) were similar between the two groups.

The plasma glucose level at $3 \mathrm{~h}$ was significantly higher in $\mathrm{G}(+)$ than in the $\mathrm{G}(-)$ group $(179.7 \pm 23.0$ vs. $113.0 \pm 23.7 \mathrm{mg} / \mathrm{dL}$, respectively; $P<0.0001$ ) (Figure 2). Two patients in the $\mathrm{G}(+)$ and two in the $\mathrm{G}(-)$ received intravenous insulin before surgery. In addition, two other patients in $\mathrm{G}(+)$ group were administered insulin within the first $3 \mathrm{~h}$ after the start of surgery. Serum levels of insulin at $3 \mathrm{~h}$ were significantly higher in the $\mathrm{G}(+)$ group than in the $\mathrm{G}(-)$ group $(9.0 \pm 6.9$ vs. $3.1 \pm 1.3 \mu \mathrm{IU} / \mathrm{ml}$, respectively; $P<0.001)$. The two groups did not significantly differ with respect to the levels of cortisol, dopamine, adrenaline, and noradrenaline at any time point. The serum level of acetoacetic acid was significantly lower at $3 \mathrm{~h}$ in the $\mathrm{G}(+)$ than in the $\mathrm{G}(-)$ group (42.3 \pm 52.5 vs. $155.5 \pm 141.9 \mu \mathrm{mol} / \mathrm{L}, P<0.05)$, as was the level of total ketone bodies $(159.4 \pm 245.8$ vs. $540.8 \pm$ $547.6 \mu \mathrm{mol} / \mathrm{L}$, respectively; $P<0.001$ ) (Figure 3 ). There were no significant differences between groups regarding the levels of 3-hydroxybutyric acid, free fatty acid or 3-MH/Cre.

\section{Discussion}

Surgical stress induces a reduction in the secretion of insulin and an increase in the release of hormones that antagonize insulin action, such as cortisol, adrenaline and noradrenaline, leading to glucose tolerance, cellular starvation, protein catabolism, and hyperglycemic ketogenesis. Our results showed the significant decrease in

\begin{tabular}{cccc} 
Table 1. Patient characteristics. & & & \\
\hline & $\mathrm{G}(+)(\mathrm{n}=11)$ & $\mathrm{G}(-)(\mathrm{n}=12)$ & $P$ values \\
\hline Male/Female & $7 / 4$ & $6 / 6$ & $P=0.51$ \\
Age (year) & $68.1 \pm 2.5$ & $65.6 \pm 2.2$ & $P=0.62$ \\
BMI (kg/m $\left.{ }^{2}\right)$ & $23.4 \pm 0.7$ & $24.5 \pm 1.0$ & $P=0.56$ \\
Operation time (min) & $379 \pm 58$ & $260 \pm 25$ & $P=0.13$ \\
Anesthetic time (min) & $500 \pm 59$ & $364 \pm 25$ & $P=0.08$ \\
Blood loss (ml) & $209 \pm 98$ & $293 \pm 174$ & $P=0.78$ \\
Transfusion volume (ml) & $3273 \pm 393$ & $3065 \pm 398$ & $P=0.48$ \\
\hline
\end{tabular}

BMI: body mass index; Data are expressed as mean \pm SD.

Table 2. Type of surgical procedure performed.

\begin{tabular}{ccc}
\hline & $\mathrm{G}(+)(\mathrm{n}=11)$ & $\mathrm{G}(-)(\mathrm{n}=12)$ \\
\hline Lap-gastrointestinal & 4 & 1 \\
Open gastrointestinal & 1 & 2 \\
Hepatectomy & 0 & 1 \\
Lap-gynecological & 1 & 1 \\
Open gynecological & 0 & 1 \\
Craniotomy & 2 & 1 \\
Cervical & 1 & 3 \\
Laminectomy & 1 & 0 \\
Nephrectomy & 1 & 1 \\
Thymectomy & 0 & 1 \\
\hline
\end{tabular}

Lap: laparoscopic 

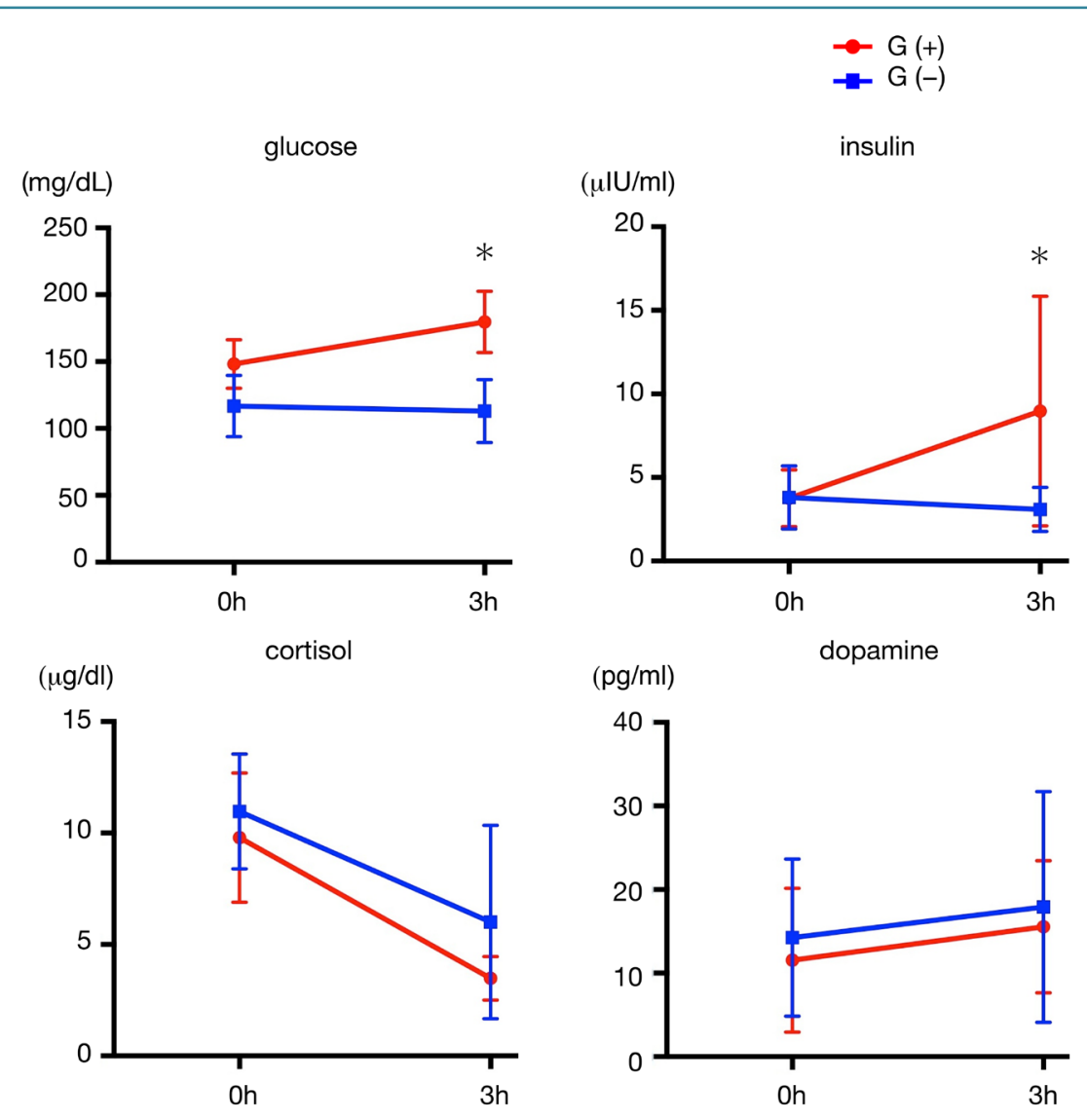

$(\mathrm{pg} / \mathrm{ml})$
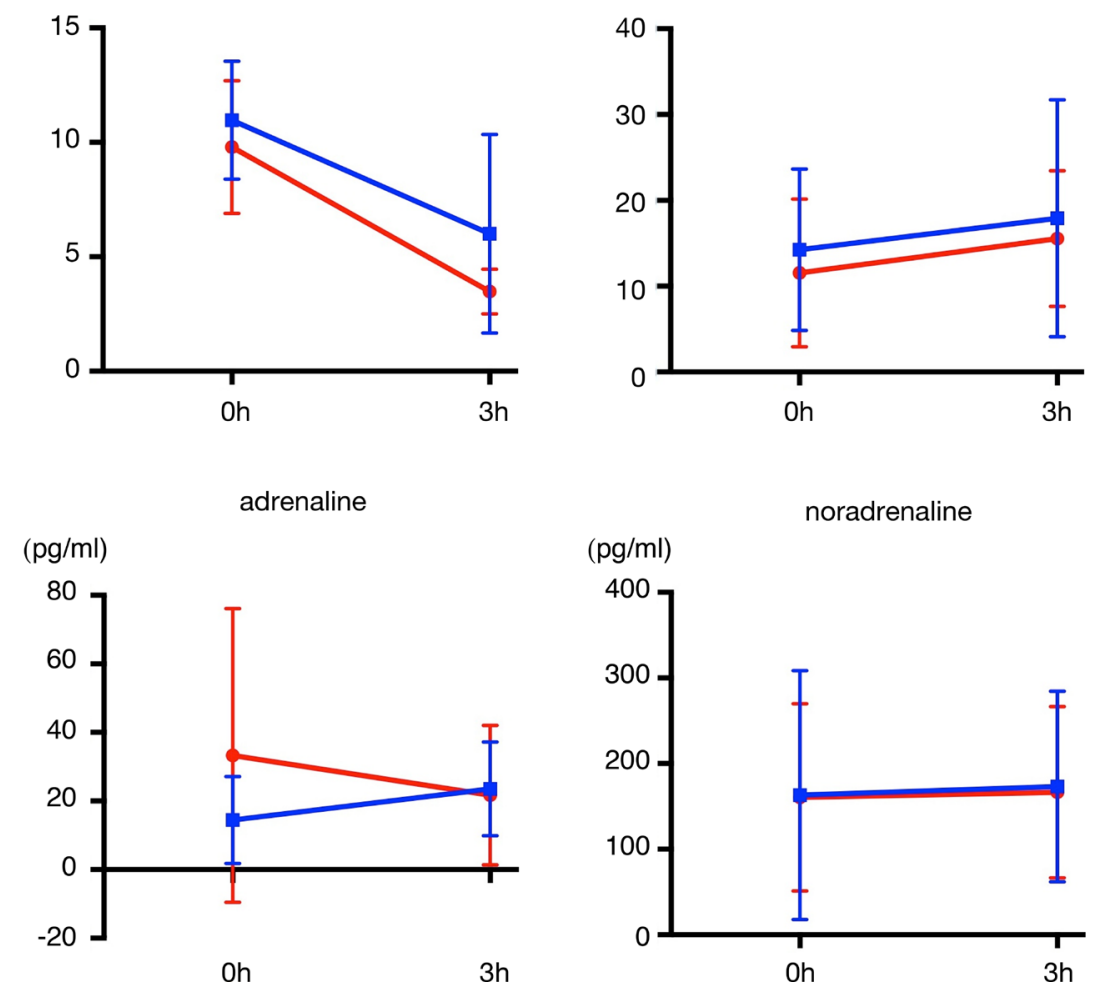

Figure 2. Plasma glucose, serum insulin, and plasma cortisol, dopamine, adrenaline, and noradrenaline levels at the start of surgery $(0 \mathrm{~h})$ and $3 \mathrm{~h}$ after the start of surgery $(3 \mathrm{~h})$ in $\mathrm{G}(+)$ and $\mathrm{G}(-)$ patients. A two-way analysis of variance was performed followed by Bonferroni's post-hoc comparisons. ${ }^{*} P<0.05$ compared with the $\mathrm{G}(-)$ group.

the serum levels of acetoacetic acid and total ketone bodies in diabetic patients receiving a glucose load during sevoflurane/remifentanil-based anesthesia; by contrast, in these patients there was no effect on protein catabolism. In this study, we could not deny the possibilities that the difference in the type of surgery procedure, the composition of transfusion, and the changes in anesthetic depth might affect on the production of these metabolites. In addition, the measurement was performed at the start of surgery and $3 \mathrm{~h}$ later. Therefore, further investigation is required to evaluate the involvement of protein catabolism in prolonged operation.

Previous studies have shown that an infusion of acetated Ringer solution containing $1 \%$ glucose ameliorated the increase in acetoacetic acid and hydroxybutyric acid compared with an infusion of the same solution without 


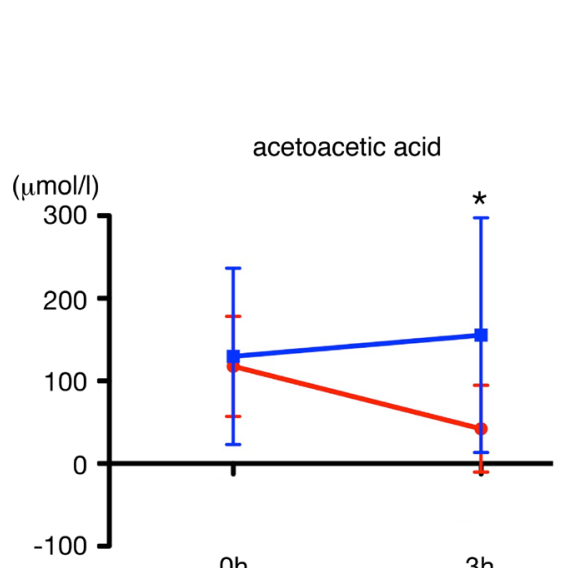

Oh

$3 h$

3-hydroxybutyric acid

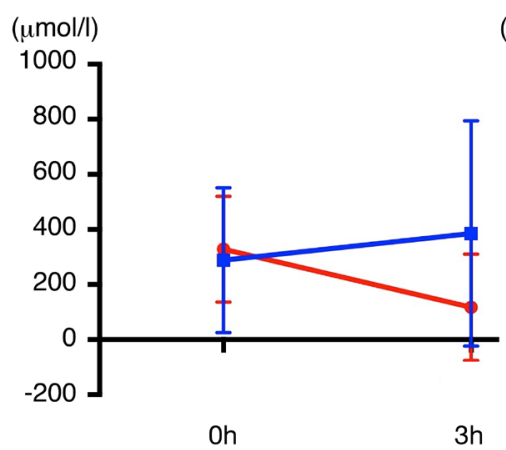

total ketone body

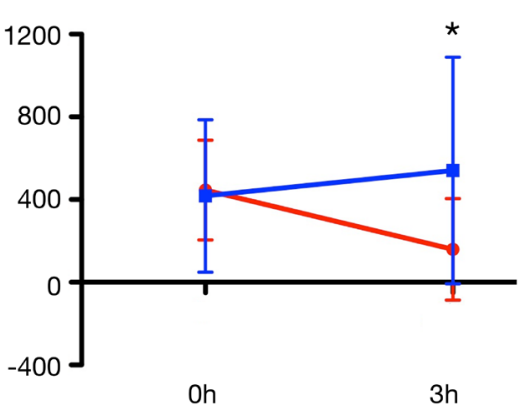

free fatty acid

$(\mu \mathrm{Eq} / \mathrm{l})$

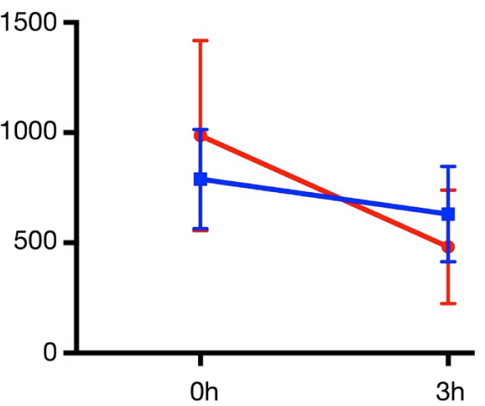

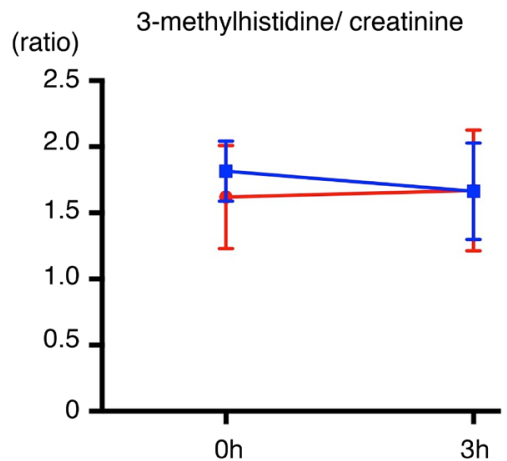

Figure 3. Plasma levels of acetoacetic acid, total ketone bodies, 3-hydroxybutyric acid, free fatty acids, and 3-methylhistidine/creatinine at the start of surgery $(0 \mathrm{~h})$ and $3 \mathrm{~h}$ after the start of surgery $(3 \mathrm{~h})$ in $\mathrm{G}(+)$ and $\mathrm{G}(-)$ patients. A two-way analysis of variance was performed followed by Bonferroni's post-hoc comparisons. ${ }^{*} P<0.05$ compared with the $\mathrm{G}(-)$ group.

glucose and $\mathrm{Mg}^{2+}$ in surgical patients under sevoflurane/fentanyl-based anesthesia [1] [8]. In another study of patients administered acetated Ringer solution with $1 \%$ glucose during sevoflurane/fentanyl-induced anesthesia, 3-MH/Cre, a marker for protein catabolism, was significantly lower than those administered acetated Ringer solution without $1 \%$ glucose [4]. However, in our study, 3-MH/Cre levels were not significantly changed within the first $3 \mathrm{~h}$ after the start of surgery in either $\mathrm{G}(+)$ or $\mathrm{G}(-)$ diabetic patients under sevoflurane/remifentanilbased anesthesia. This finding is consistent with a previous report on patients undergoing minor surgery and anesthetized with sevoflurane/remifentanil: the levels of ketone bodies were lower in those who received a glucose load than in those who did not, whereas there were no significant differences in 3-MH/Cr under remifenta- 
nil-based anesthesia in patients [6]. In our series of diabetic patients under remifentanil-based anesthesia, there were no elevations in the levels of hormones that antagonize the actions of insulin such as cortisol, adrenaline and noradrenaline (Figure 2). Thus, our results suggest that remifentanil itself is a strong inhibitor of surgical stress responses, including protein sparing. The continuous infusion of high-dose remifentanil during elective gastrectomy was recently shown to reduce postoperative insulin resistance compared with the use of low-dose remifentanil, while postoperative muscle protein catabolism was unchanged [9]. Taken together, these results suggest that remifentanil has an inhibitory effect on insulin tolerance and protein sparing, possibly by inhibiting the production of stress hormones.

In a study using rats, glucose infused at a low rate suppressed muscle protein breakdown via a mechanism proposed to involve suppression of the ubiquitin-proteasome pathway activated by insulin signaling [10]. That finding suggests that glucose and insulin therapy can effectively maintain insulin sensitivity in the perioperative period. However, there is little correlation between hyperglycemia and mortality in diabetic vs. non-diabetic patients [11]. The NICE-SUGAR study found that intensive insulin therapy increases the mortality rate as a result of severe hypoglycemia [12]. Intraoperative hyperglycemia has also been linked to increased mortality whereas hypoglycemia is more likely to develop in patients with diabetes mellitus [13]. In another study, patients undergoing major liver resection but not receiving perioperative glucose and insulin to maintain normoglycemia experienced severe hypoglycemia [14], which occurred with a higher incidence in diabetic than in non-diabetic patients. In addition, 1-year mortality was higher in diabetic patients with plasma glucose levels similar to those of non-diabetic patients (6 mmol/L or $108 \mathrm{mg} / \mathrm{dL}$ ) during elective non-cardiac surgery [11], suggesting that plasma glucose should be maintained higher level in patients with diabetes mellitus. Although the efficacy of glucose supplementation without insulin in diabetic patients is unknown, Leuven study revealed the strong correlations between rapid hypoglycemia induced by intensive glucose-insulin therapy and an increase in mortality rate in diabetic patients as well as between a decrease in plasma glucose levels and lower mortality in non-diabetic patients [15].

A preoperative carbohydrate load improves postoperative insulin resistance while intraoperative glucose and insulin supplementation inhibit surgery-induced gluconeogenesis and the breakdown of skeletal muscle proteins [16] [17]. In our study, patients had fasted $8 \mathrm{~h}$ before surgery, which would have decreased glucose levels [13]: thus, the absence of preoperative glucose loading may have induced catabolism, thereby increasing free fatty acid, and, in turn, ketoacidosis.

\section{Conclusion}

Our study reveals that, in diabetic patients undergoing surgery with remifentanil-based anesthesia, administration of an intraoperative glucose load can suppress the elevation of acetoacetic acid and total ketone bodies, but has no effect on protein sparing, or the production of stress hormones. These results suggest that, in contrast to fentanyl, in diabetic patients protein sparing is inhibited by remifentanil-based anesthesia while the provision of a glucose load inhibits ketogenesis.

\section{Competing Interest}

The authors have no conflicts of interest to declare, financial or otherwise.

\section{Authors' Contribution}

MN, MH-M, AM, and YK participated in study design. MM, KM, and MN performed the preparation of the blood samples for measurement. TS and TY performed statistical analysis. MH-M drafted the manuscript. All authors read and approved the final manuscript.

\section{Acknowledgements}

No one other than the authors contributed substantially to the performance of this study or to the drafting of the manuscript.

\section{References}

[1] Schricker, T., Lattermann, R. and Carli, F. (2005) Intraoperative Protein Sparing with Glucose. Journal of Applied 
Physiology, 99, 898-901.

[2] Pomposelli, J.J., Baxter, J.K., Babineau, T.J., Pomfret, E.A., Driscoll, D.F., Forse, R.A. and Bistrian, B.R. (1998) Early Postoperative Glucose Control Predicts Nosocomial Infection Rate in Diabetic Patients. Journal of Parenteral and Enteral Nutrition, 22, 77-81. http://dx.doi.org/10.1177/014860719802200277

[3] Oliver, M.F. (2006) Sudden Cardiac Death: The Lost Fatty Acid Hypothesis. QJM, 99, 701-709. http://dx.doi.org/10.1093/qjmed/hcl084

[4] Yamasaki, K., Inagaki, Y., Mochida, S., Funaki, K., Takahashi, S. and Sakamoto, S. (2010) Effect of Intraoperative Acetated Ringer's Solution with 1\% Glucose on Glucose and Protein Metabolism. Journal of Anesthesia, 24, 426-431. http://dx.doi.org/10.1007/s00540-010-0926-1

[5] Winterhalter, M., Brandl, K., Rahe-Meyer, N., Osthaus, A., Hecker, H., Hagl, C., Adams, H.A. and Piepenbrock, S. (2008) Endocrine Stress Response and Inflammatory Activation during CABG Surgery. A Randomized Trial Comparing Remifentanil Infusion to Intermittent Fentanyl. European Journal of Anaesthesiology, 25, 326-335. http://dx.doi.org/10.1017/S0265021507003043

[6] Kambe, N., Tanaka, K., Kakuta, N., Kawanishi, R. and Tsutsumi, Y.M. (2014) The Influence of Glucose Load on Metabolism during Minor Surgery Using Remifentanil-Induced Anesthesia. Acta Anaesthesiologica Scandinavica, 58, 948-954. http://dx.doi.org/10.1111/aas.12335

[7] Hirsch, I.B., McGill, J.B., Cryer, P.E. and White, P.F. (1991) Perioperative Management of Surgical Patients with Diabetes Mellitus. Anesthesiology, 74, 346-359. http://dx.doi.org/10.1097/00000542-199102000-00023

[8] Yokoyama, T., Suwa, K., Yamasaki, F., Yokoyama, R., Yamashita, K. and Sellden, E. (2008) Intraoperative Infusion of Acetated Ringer Solution Containing Glucose and Ionized Magnesium Reduces Ketogenesis and Maintains Serum Magnesium. Asia Pacific Journal of Clinical Nutrition, 17, 525-529.

[9] Taniguchi, H., Sasaki, T., Fujita, H., Takano, O., Hayashi, T., Cho, H., Yoshikawa, T. and Tsuburaya, A. (2013) The Effect of Intraoperative Use of High-Dose Remifentanil on Postoperative Insulin Resistance and Muscle Protein Catabolism: A Randomized Controlled Study. International Journal of Medical Sciences, 10, 1099-1107. http://dx.doi.org/10.7150/ijms.5924

[10] Mikura, M., Yamaoka, I., Doi, M., Kawano, Y., Nakayama, M., Nakao, R., Hirasaka, K., Okumura, Y. and Nikawa, T. (2009) Glucose Infusion Suppresses Surgery-Induced Muscle Protein Breakdown by Inhibiting Ubiquitin-Proteasome Pathway in Rats. Anesthesiology, 110, 81-88. http://dx.doi.org/10.1097/ALN.0b013e318190b6c1

[11] Abdelmalak, B.B., Knittel, J., Abdelmalak, J.B., Dalton, J.E., Christiansen, E., Foss, J., Argalious, M., Zimmerman, R. and Van den Berghe, G. (2014) Preoperative Blood Glucose Concentrations and Postoperative Outcomes after Elective Non-Cardiac Surgery: An Observational Study. British Journal of Anaesthesia, 112, 79-88. http://dx.doi.org/10.1093/bja/aet297

[12] Finfer, S., Chittock, D.R., Su, S.Y., Blair, D., Foster, D., Dhingra, V., Bellomo, R., Cook, D., Dodek, P., Henderson, W.R., et al. (2009) Intensive versus Conventional Glucose Control in Critically Ill Patients. The New England Journal of Medicine, 360, 1283-1297. http://dx.doi.org/10.1056/NEJMoa0810625

[13] Sieber, F.E., Smith, D.S., Traystman, R.J. and Wollman, H. (1987) Glucose: A Reevaluation of Its Intraoperative Use. Anesthesiology, 67, 72-81. http://dx.doi.org/10.1097/00000542-198707000-00013

[14] Sato, H., Lattermann, R., Carvalho, G., Sato, T., Metrakos, P., Hassanain, M., Matsukawa, T. and Schricker, T. (2010) Perioperative Glucose and Insulin Administration while Maintaining Normoglycemia (GIN Therapy) in Patients Undergoing Major Liver Resection. Anesthesia and Analgesia, 110, 1711-1718. http://dx.doi.org/10.1213/ANE.0b013e3181d90087

[15] Van den Berghe, G., Wilmer, A., Hermans, G., Meersseman, W., Wouters, P.J., Milants, I., Van Wijngaerden, E., Bobbaers, H. and Bouillon, R. (2006) Intensive Insulin Therapy in the Medical ICU. The New England Journal of Medicine, 354, 449-461. http://dx.doi.org/10.1056/NEJMoa052521

[16] Ljungqvist, O., Nygren, J. and Thorell, A. (2002) Modulation of Post-Operative Insulin Resistance by Pre-Operative Carbohydrate Loading. Proceedings of the Nutrition Society, 61, 329-336. http://dx.doi.org/10.1079/PNS2002168

[17] Nygren, J.O., Thorell, A., Soop, M., Efendic, S., Brismar, K., Karpe, F., Nair, K.S. and Ljungqvist, O. (1998) Perioperative Insulin and Glucose Infusion Maintains Normal Insulin Sensitivity after Surgery. American Journal of Physiology, 275, E140-E148.

\section{List of Abbreviations}

3-MH; 3-methyl histidine, Cr; creatinine 